\title{
Genetic Diversity Analysis of Nine Narcissus Based on Morphological Characteristics and Random Amplified Polymorphic DNA Markers
}

\author{
Xiao-min Liu, Xin-zhi Zhang, Yi-min Shi, and Dong-qin Tang ${ }^{1}$ \\ School of Agriculture and Biology, Shanghai Jiao Tong University, \\ Shanghai, 200240, China
}

Additional index words. daffodil, morphology, molecular marker, genetic diversity, genetic relationship

\begin{abstract}
Genetic diversity of Narcissus was systematically studied on both morphological and molecular levels. Twenty-four characteristics of nine narcissi were observed and their differences evaluated by clustering method. The results showed that nine narcissi can be divided into two subclusters: one comprised by Narcissus pseudonarcissus, the other by Chinese Narcissus. The morphological diversity among five cultivars of $N$. pseudonarcissus is higher than that among four ecotypes of Chinese Narcissus (Narcissus tazetta var. chinensis). There are seven morphological characteristics in $N$. pseudonarcissus presenting obvious variations with coefficients from $33.33 \%$ to $91.67 \%$. Only five morphological characteristics in Chinese Narcissus present certain variations with coefficients from $37.04 \%$ to $51.79 \%$. On DNA level, two clusters are distantly related too. Based on the random amplified polymorphic DNA (RAPD) markers, 13 out of 40 random primers yielded scorable polymorphisms between samples. Wide variations in banding profiles between cultivars or between ecotypes were observed with nearly every primer tested. Among 95 band positions that were scored for all the 9 narcissi, 81 are polymorphic $(85.26 \%)$. Cluster analysis of the calculated similarity matrix revealed that the genetic diversity between these individuals within the same section is low. However, the genetic diversity between two sections is obviously higher. Taken together, the methods combined morphological characteristics and RAPD technique allow a deep evaluation of the variation of Narcissus on both section level and cultivar/ecotype level.
\end{abstract}

Narcissus, a flowering bulbous plant of the Amaryllidaceae family, is a typical Mediterranean genus, also named daffodil. As one of the most important commercial bulbous crops in the floriculture industry, Narcissus is used as cut flowers and potted plants worldwide. After a long history of cultivation, complex breeding programs of daffodils over the past 150 years have resulted in more than 30,000 registered cultivars (Kington, 2014; Könyves et al., 2011), showing richful genetic diversity in this genus.

Genetic diversity in cultivated crops is essential for successful breeding and creation of new cultivars. Information on genetic diversity patterns can provide insight into the conservation, evaluation, and use of the germplasm resources (Franco et al., 2001; Zhang and Dai, 2010). The methods for analysis of genetic diversity in plants were well developed in the last decades, commonly based on the morphological characteristics,

Received for publication 13 July 2016. Accepted for publication 16 Sept. 2016.

This research was supported by Shanghai Chongming Project (grant 13391912504) and the Key Science and Technology Foundation (grant 13391901002) from Science and Technology Commission of Shanghai Municipality, Shanghai, China.

${ }^{1}$ Corresponding author. E-mail: dqtang@sjtu.edu.cn. seed proteins, isozymes, and DNA markers (Gepts, 1993). The method based on morphological characteristics has become one of the dominant strategies due to its easy operation and intuitive results, and has been applied for variety of plants, such as cultivated common bean (Singh et al., 1991), cotton (Tatineni et al., 1996), wheat (Marić et al., 2004), and pea (Tar'an et al., 2005). Traditionally, the identification of narcissus varieties, cultivars, and clones for breeding, or the estimation of genetic relationships, begins with the observation of the morphological characteristics of the plant. In this regard, some reports have been published on the agro-morphological recording for germination, growth, propagation, cultivation, and breeding of narcissus (Copete et al., 2014; Larrinaga et al., 2009; Marques et al., 2007; Medrano et al., 2005; Nuñez et al., 2003), which provide fundamental information for the analysis of genetic diversity on the morphological level. However, analysis of the genetic diversity of narcissus still needs to be conducted in a systematic and quantitative manner (Nuñez et al., 2003; Santos-Gally et al., 2012).

Plant morphological features, such as plant height, leaf shape and size, and even certain flower traits, are often both environmentally and developmentally dependent, morphological recording is therefore time consuming and laborious. Another way to characterize plants is the utilization of genetic tools, such as the RAPD, amplification fragment length polymorphism (AFLP) (Idrissi et al., 2015; Warwick et al., 2006), simple sequence repeat (SSR) (Rafeipour et al., 2016), intersimple sequence repeats (ISSR) (Zhang and Dai, 2010), and sequencetagged sites (Patzak, 2001). For instance, AFLP markers were used to distinguish two taxa of narcissus (Tucci et al., 2004), evaluate the effect of radiation on regeneration of Chinese Narcissus (N. tazetta var. chinensis), and analyze the genetic variation ( $\mathrm{Lu}$ et al., 2007). ISSR and internal transcribed spacer markers were also used for species identification in narcissus (Jiménez et al., 2009). In addition, Hodgins and Barrett (2007) investigated cpDNA sequence and nuclear microsatellite variation among populations of the wild daffodil (Narcissus triandrus). More recently, RAPD technique has gained its central position for genetic diversity studies due to its low expense and high efficiency (Ambade et al., 2015; Bradakci, 2001; Kocsis et al., 2015; Kour et al., 2016). In daffodils, RAPD was once applied to analyze their germplasm resources, variety identifications (Chen et al., 2002, 2003; Dong, 2012; Wu et al., 2005; Zhu, 2003), and population genetic structures (Colling et al., 2010). In this paper, RAPD analysis is applied to assess the degree of polymorphism within individual narcissi and different sections and the result is combined with the morphological characteristics to evaluate the genetic diversity of the plant.

Chinese Narcissus is particularly popular for its flower fragrance and multiflowers in inflorescence, and has been used as ornamental bulbs for a longtime in China. Though floriculture industry produces only two main cultivars, Jinzhanyintai and Yulinglong, several ecotypes have been emerged during the long history of cultivation in different areas. Narcissus pseudonarcissus is also highly appreciated for its colorful flowers and flower size, and becomes popular in China during recent decades. In China, it is true to introduce and plant many narcissus cultivars (including $N$. pseudonarcissus) every year, but most of them cannot be used as commercial production again. After decades' introduction and selected breeding practice, we have obtained several bud sport cultivars of $N$. pseudonarcissus recently, including Shangnong Wanxia, Shangnong Zaochun, Shangnong Ruhuang, Shangnong Dieying, and Shangnong Hongying, which was bred through spontaneous mutants from 'Professor Einstein', 'Dutch Master', 'SlimWhitman', 'Sovereign', and 'Delibes', respectively, possessing different flowering time, strong adaptability to local climate, and stable morphological characteristics. These narcissi belong to two subgenuses (Hermione and Narcissus for N. tazetta var. chinensis and $N$. pseudonarcissus, respectively) and two sections (Hermione and Pseudonarcissus for $N$. tazetta var. chinensis and N. pseudonarcissus, respectively) (Brickell, 2008; Kington, 1998). Their morphologic appearances are 
apparently quite distinct, and therefore they are chosen to evaluate their genetic diversity. In brief, the project is designed with two primary objectives: to ascertain the genetic affinities or the level of differentiation between the two sections of Narcissus as well within nine individual narcissi, and to compare the genetic distances estimated respectively from morphological characteristics and RAPDs.

\section{Materials and Methods}

\section{Plant materials}

Two sections, total nine individual narcissi were used in the present study, including five cultivars of $N$. pseudonarcissus (in section Pseudonarcissus) and four ecotypes of Chinese Narcissus (N. tazetta var. chinensis) (in section Hermione, syn. Tazettae) (Table 1). The bulb size was in commercial standard, $12-14 \mathrm{~cm}$ and $14-16 \mathrm{~cm}$ in perimeter for Pseudonarcissus and Chinese Narcissus, respectively. These narcissi were planted in mid-Nov. 2014 in the horticultural farm (field) of Shanghai Jiao Tong University, Shanghai, China, under identical cultivating conditions, including fertilization, irrigation, and disease prevention methods.

\section{Methods}

Expt. 1. Genetic diversity analysis of Narcissus based on morphological characteristics.

Measurement of morphological characteristics. The growth parameters were recorded at different periods. The sprouting period was counted by the days until $20 \%$ of plants in sprouting. After leaves were fully elongated, ramet number, leaf number, plant height (from the stem base to the top of the longest leaf), leaf width (at $1 / 3$ of the total leaf height), and leaf thickness (Leaf pachymeter, China) were recorded or measured. The numbers of flowering stem, flower bud, and flower were recorded at 3-d interval from flowering stem appearing to petal fading. Then flowering stem appearing period was counted by the interval days between $20 \%$ plant sprouting and $40 \%$ flowering stem appearing. Flower bud coloring period was counted by the interval days between $40 \%$ flowering stem appearing and $40 \%$ flower bud coloring. The early, full, and late blossoming periods were counted by each interval days between $40 \%$ flower bud coloring, $20 \%$ full blossom, $50 \%$ full blossom, and $40 \%$ petal fading, respectively. Plant withering period was counted by the interval days between $40 \%$ petal fading and $20 \%$ plant withering. In addition, flowering stem strength (Stem Strength Apparatus, China), flowering stem height (from the base to the top of flowering stem), flower diameter, catacorolla diameter, and petal length and weight were also measured. The color of flower bud, petal, catacorolla, and leaf was described according to the Royal Horticultural Society Color Card (RHSCC, mini version).

All the samples thus form 24 morphological characteristics consisting of 20 quantitative and 4 qualitative characteristics. The qualitative characteristics were coded as $0-4$ (Table 2).

\section{Statistical analysis}

For each phenological period, the percentage was counted based on the population $(n>200$ plants). For other index, means ( $n=$ 20), standard error, and the range were calculated and used for the analysis. The $\mathrm{CV}$ was calculated as (sD/average) $\times 100 \%$.
Statistical analysis was performed by SPSS 14.0. Variance (one-way analysis of variance) and means were compared by the Duncan's New Multiple Range test $(P<$ $0.05)$. To illustrate the genetic diversity, the squared Euclidean distance was calculated. Clustering was conducted by hierarchical clustering analysis with between-groups linkage method.

Expt. 2. Evaluating the genetic diversity by RAPD markers.

DNA isolation and polymerase chain reaction amplification. Young leaf samples (5-10 g fresh weight) were collected from five individual plants for each narcissus. Total genomic DNA was extracted using a modified CTAB method (Doyle and Doyle, 1987). Isolated DNA was frozen at $-80^{\circ} \mathrm{C}$. Each polymerase chain reaction (PCR) contained $25 \mu \mathrm{L}$ reaction volume consisting of $1 \mu \mathrm{L}$ template DNA $\left(100 \mathrm{ng} \cdot \mu \mathrm{L}^{-1}\right), 1 \mu \mathrm{L}$ primer $(10 \mu \mathrm{M}), 12.5 \mu \mathrm{L}$ Premix Taq (TaKaRa, Dalian, China), and $10.5 \mu \mathrm{L} \mathrm{ddH_{2 }} \mathrm{O}_{\text {. }}$

PCR amplification was performed on a Chromo4 opticon Thermal Cycler (BioRad, CA) programed starting with $5 \mathrm{~min}$ at $95{ }^{\circ} \mathrm{C}$, followed by 32 cycles with 1) $30 \mathrm{~s}$ at $94{ }^{\circ} \mathrm{C}$, 2) $30 \mathrm{~s}$ at $41^{\circ} \mathrm{C}$, and 3) $2 \mathrm{~min}$ at $72{ }^{\circ} \mathrm{C}$, and a final extension at $72^{\circ} \mathrm{C}$ for $3 \mathrm{~min}$ followed by a slow cooling to room temperature. Amplification products were analyzed by electrophoresis in $1.5 \%$ agarose gels.

Recording of observations and data analysis. In the following descriptions, a "band" refers a visible amplification product at a given gel position. Bands on RAPD gels were scored as 1 if present and reproducible, or 0 if absent. A total of 40 random, 10 -mer primers (Sangon Biotech (Shanghai)

Table 1. Source and name of plant materials.

\begin{tabular}{|c|c|c|c|c|}
\hline No. & Plant name & Abbreviation for plant name & Division $^{2}$ & Source \\
\hline 1 & Narcissus pseudonarcissus 'Shangnong Wanxia' & Shangnong Wanxia & Large cupped & Shanghai, China \\
\hline 3 & N. pseudonarcissus 'Shangnong Ruhuang' & Shangnong Ruhuang & Large cupped & Shanghai, China \\
\hline 4 & N. pseudonarcissus 'Shangnong Dieying' & Shangnong Dieying & Split corona & Shanghai, China \\
\hline 6 & Zhangzhou Narcissus 'Yulinglong' & Zhangzhou 'Yulinglong' & Tazettae & Fujian, China \\
\hline 7 & Zhangzhou Narcissus 'Jinzhanyintai' & Zhangzhou 'Jinzhanyintai' & Tazettae & Fujian, China \\
\hline 8 & Putuo Narcissus ‘Jinzhanyintai’ & Putuo ‘Jinzhanyintai' & Tazettae & Zhejiang, China \\
\hline
\end{tabular}

${ }^{\mathrm{z}}$ Royal Horticultural Society classification term for daffodils.

Table 2. Codes for qualitative characteristics.

\begin{tabular}{|c|c|c|c|}
\hline No. & Characteristics & Code & Encoding details \\
\hline \multirow[t]{2}{*}{1} & Bud color & 0 & White (RHS155C) \\
\hline & & 2 & Light green yellow (RHS2D) \\
\hline \multirow[t]{4}{*}{2} & Catacorolla color & 0 & Yellow (RHS12A) \\
\hline & & 1 & Yellow (RHS6A) \\
\hline & & 2 & Yellow (RHS7D) \\
\hline & & 3 & Orange for top catacorrlla (RHS24A) and yellow for bottle catacorolla (RHS12A) \\
\hline \multirow{2}{*}{3} & & 1 & Light yellow (RHS4D) \\
\hline & & 2 & Yellow (RHS6A) \\
\hline \multirow[t]{2}{*}{4} & Leaf color & 0 & Green (RHS137C) \\
\hline & & 1 & Deep green (RHS137A) \\
\hline
\end{tabular}


Co Ltd, China) were used for initial screening (Table 3). Specific primers, out of forty primers with scorable polymorphisms, were further used to amplify all DNA samples. Based on the scored bands obtained by these primers, the cluster analysis was performed with unweighted pair group method arithmetic averages method by NTSYS 2.10 software in SAHN model, the dendrogram was then drew by tree plot method.

\section{Results}

\section{Phenological period recording and analysis of agro-morphological characteristics of vegetable organs}

Overall, the phenological periods of five cultivars of $N$. pseudonarcissus come later than four ecotypes of Chinese Narcissus
(Table 4). After planting, Chinese Narcissus takes $30-39$ d for $20 \%$ plants to sprout, whereas $N$. pseudonarcissus takes 95-110 d. Flowering stem appearing period lasts $13-15 \mathrm{~d}$ and 13-24 d for Chinese Narcissus and $N$. pseudonarcissus, respectively. It takes additional $14-15 \mathrm{~d}$ and $8-15 \mathrm{~d}$ from $40 \%$ flowering stem appearing to $40 \%$ flower bud coloring for Chinese Narcissus and N. pseudonarcissus, respectively. Early blossom period of $N$. pseudonarcissus $(2-3 \mathrm{~d})$ is much shorter than Chinese Narcissus (9-10 d), whereas there is no obvious difference on the full blossom period. It is noteworthy too that Chinese Narcissus lasts a longer period (10-21 d) from $50 \%$ full blossom to $40 \%$ petal fading than $N$. pseudonarcissus $(6-10 \mathrm{~d})$, but it experiences a shorter withering period (30-34 d) than N. pseudonarcissus (45-57 d).

Table 3. The random primers for RAPD.

\begin{tabular}{rlllll}
\hline No. & Primer code & Primer sequence & No. & Primer code & Primer sequence \\
\hline 1 & S4 & GGACTGGAGT & 21 & S183 & CAGAGGTCCC \\
2 & S6 & TGCTCTGCCC & 22 & S245 & TTGGCGGCCT \\
3 & S7 & GGTGACGCAG & 23 & S283 & ACAGCCTGCT \\
4 & S8 & GTCCACACGG & 24 & S287 & AGAGCCGTCA \\
5 & S10 & CTGCTGGGAC & 25 & S295 & AGTCGCCCTT \\
6 & S11 & GTAGACCCGT & 26 & S297 & GACGTGGTGA \\
7 & S13 & TTCCCCCGCT & 27 & S303 & TGGCGCAGTG \\
8 & S17 & AGGGAACGAG & 28 & S340 & ACTTTGGCGG \\
9 & S22 & TGCCGAGCTG & 29 & S417 & TCAGTCCGGG \\
10 & S23 & AGTCAGCCAC & 30 & S476 & CCAAGCTGCC \\
11 & S24 & AATCGGGCTG & 31 & S488 & CTCCAGCGGA \\
12 & S48 & GTGTGCCCCA & 32 & S1019 & GGCAGTTCTC \\
13 & S58 & GAGAGCCAAC & 33 & S1505 & CCCACTAGAC \\
14 & S68 & TGGACCGGTG & 34 & S1510 & ACTGCCCGAC \\
15 & S70 & TGTCTGGGTG & 35 & S1515 & TTACGGTGGG \\
16 & S75 & GACGGATCAG & 36 & S1516 & CCTGCGACAG \\
17 & S96 & AGCGTCCTCC & 37 & S1519 & AGCCTCGGTT \\
18 & S121 & ACGGATCCTG & 38 & S1520 & TGCGCTCCTC \\
19 & S123 & CCTGATCACC & 39 & S1521 & GTCTCGTCGG \\
20 & S154 & TGCGGCTGAG & 40 & S1522 & AACGTACGCG \\
\hline
\end{tabular}

$\mathrm{RAPD}=$ random amplified polymorphic DNA.

In terms of agro-morphological characteristics of vegetable organs, the two sections exhibit a significant difference (Table 5). The parameters including the ramet number, leaf number, plant height, leaf width, and leaf thickness are higher in four ecotypes of Chinese Narcissus than these in five cultivars of N. pseudonarcissus. For instance, the ramet number and leaf number are 3.40 5.30 and $12.40-18.40$ in Chinese Narcissus vs. $2.50-3.40$ and $8.00-14.80$ in N. pseudonarcissus. And leaf width and leaf thickness are $2.35-3.12 \mathrm{~cm}$ and $1.33-1.72 \mathrm{~mm}$ in Chinese Narcissus vs. $1.10-2.07 \mathrm{~cm}$ and $0.84-1.27 \mathrm{~mm}$ in $N$. pseudonarcissus. In addition, the leaf color of Chinese Narcissus (RHS137A) is deeper than N. pseudonarcissus (RHS137C), but no difference within the same section.

\section{Analysis of morphological characteristics of inflorescences and flowers}

The two sections of narcissus display a significant difference in the morphological characteristics of inflorescences (Table 6). The numbers of flowering stem in Chinese Narcissus (1.80-5.10) are significant more than $N$. pseudonarcissus (1.00-1.60), but their flowering stem strengths are in general weaker. The highest $(35.13 \mathrm{~cm})$ and lowest $(23.06 \mathrm{~cm})$ flowering stem heights are present in Zhangzhou Narcissus 'Yulinglong' and Chongming Narcissus 'Jinzhanyintai', respectively. There exists a positive relationship between the flowering stem number and the flower number (Table 6); the maximum number of flowering stem (5.10) and flower number (31.70) are observed in Putuo Narcissus 'Jinzhanyintai', and the minimum number of flowering stem (1.00) and flower number (1.00) are present in three cultivars of $N$. pseudonarcissus.

Table 4. Phenological periods of nine narcissi.

\begin{tabular}{|c|c|c|c|c|c|c|c|}
\hline Narcissus & $\begin{array}{l}\text { Sprouting } \\
\text { period }^{\mathrm{z}}\end{array}$ & $\begin{array}{c}\text { Flowering } \\
\text { stem appearing } \\
\text { period }\end{array}$ & $\begin{array}{l}\text { Flower } \\
\text { bud coloring } \\
\text { period }\end{array}$ & $\begin{array}{c}\text { Early } \\
\text { blossom } \\
\text { period }\end{array}$ & $\begin{array}{c}\text { Full } \\
\text { blossom } \\
\text { period }\end{array}$ & $\begin{array}{c}\text { Late } \\
\text { blossom } \\
\text { period }\end{array}$ & $\begin{array}{c}\text { Plant } \\
\text { withering } \\
\text { period }\end{array}$ \\
\hline Shangnong Wanxia & 111 & 20 & 10 & 2 & 2 & 10 & 49 \\
\hline Shangnong Zaochun & 95 & 18 & 11 & 3 & 4 & 6 & 57 \\
\hline Shangnong Dieying & 103 & 24 & 8 & 2 & 4 & 8 & 45 \\
\hline Shangnong Hongying & 100 & 13 & 19 & 2 & 2 & 10 & 48 \\
\hline Zhangzhou 'Yulinglong' & 33 & 13 & 14 & 9 & 3 & 17 & 30 \\
\hline Chongming 'Jinzhanyintai' & 39 & 14 & 15 & 10 & 3 & 10 & 34 \\
\hline
\end{tabular}

${ }^{\mathrm{z}}$ Days from planting to sprouting, the others mean the days between two periods.

Table 5. Agro-morphological characters of vegetative organs in nine narcissi.

\begin{tabular}{llccrc}
\hline Narcissus & Ramet number & Leaf number & Plant ht $(\mathrm{cm})$ & Leaf width $(\mathrm{cm})$ & Leaf thickness $(\mathrm{mm})$ \\
\hline Shangnong Wanxia & $3.40 \pm 0.16 \mathrm{bc}^{\mathrm{z}}$ & $14.80 \pm 0.76 \mathrm{c}$ & $31.80 \pm 0.90 \mathrm{bc}$ & $1.21 \pm 0.05 \mathrm{a}$ & $0.91 \pm 0.10 \mathrm{a}$ \\
Shangnong Zaochun & $2.90 \pm 0.18 \mathrm{ab}$ & $8.20 \pm 0.36 \mathrm{a}$ & $28.34 \pm 0.29 \mathrm{a}$ & $1.55 \pm 0.05 \mathrm{~b}$ & $0.98 \pm 0.01 \mathrm{a}$ \\
Shangnong Ruhuang & $3.00 \pm 0.15 \mathrm{ab}$ & $8.00 \pm 0.33 \mathrm{a}$ & $30.62 \pm 0.87 \mathrm{bc}$ & $1.96 \pm 0.07 \mathrm{c}$ & $1.27 \pm 0.02 \mathrm{~b}$ \\
Shangnong Dieying & $2.80 \pm 0.20 \mathrm{ab}$ & $10.60 \pm .97 \mathrm{~b}$ & $29.80 \pm 0.53 \mathrm{ab}$ & $1.10 \pm 0.04 \mathrm{a}$ & $0.84 \pm 0.01 \mathrm{a}$ \\
Shangnong Hongying & $2.50 \pm 0.17 \mathrm{a}$ & $10.90 \pm 0.57 \mathrm{~b}$ & $28.52 \pm 0.50 \mathrm{a}$ & $2.07 \pm 0.03 \mathrm{c}$ & $0.95 \pm 0.03 \mathrm{a}$ \\
Zhangzhou 'Yulinglong' & $3.80 \pm 0.36 \mathrm{~d}$ & $14.30 \pm 1.05 \mathrm{c}$ & $51.52 \pm 0.87 \mathrm{e}$ & $3.12 \pm 0.03 \mathrm{~g}$ & $1.72 \pm 0.04 \mathrm{~d}$ \\
Zhangzhou 'Jinzhanyintai' & $5.10 \pm 0.28 \mathrm{e}$ & $17.50 \pm 0.83 \mathrm{~d}$ & $38.44 \pm 0.70 \mathrm{~d}$ & $2.93 \pm 0.07 \mathrm{f}$ & $1.62 \pm 0.04 \mathrm{c}$ \\
Putuo 'Jinzhanyintai' & $5.30 \pm 0.21 \mathrm{e}$ & $18.40 \pm 0.52 \mathrm{~d}$ & $32.03 \pm 0.65 \mathrm{c}$ & $2.72 \pm 0.05 \mathrm{e}$ & $1.54 \pm 0.06 \mathrm{c}$ \\
Chongming 'Jinzhanyintai' & $3.40 \pm 0.40 \mathrm{bc}$ & $12.40 \pm 1.48 \mathrm{bc}$ & $27.79 \pm 0.53 \mathrm{a}$ & $2.35 \pm 0.07 \mathrm{~d}$ & $1.33 \pm 0.05 \mathrm{~b}$ \\
\hline
\end{tabular}

${ }^{\mathrm{z}}$ The different lowercase letter in the same column indicates significant difference by Duncan's multiple range test at $P<0.05$. 
A significant difference was also observed in morphological characteristics of flowers between the two sections (Table 7). Narcissus pseudonarcissus plants are larger in flower diameter, catacorolla diameter, petal length, and petal width than Chinese Narcissus. In details, N. pseudonarcissus is 8.40 $10.55 \mathrm{~cm}$ and $3.09-6.47 \mathrm{~cm}$ in flower and catacorolla diameters, respectively, vs. 3.85$4.26 \mathrm{~cm}$ and $1.49-2.93 \mathrm{~cm}$ for Chinese Narcissus, respectively. Narcissus pseudonarcissus is $3.23-4.47 \mathrm{~cm}$ and $3.00-3.97 \mathrm{~cm}$ in petal length and width, respectively, much higher than Chinese Narcissus. Within individual section, a significant difference was observed for the flower characteristics among five cultivars of $N$. pseudonarcissus, but no obvious difference in Chinese Narcissus.

We then recorded flower bud color, catacorolla color, and petal color base on RHSCC (Table 8; Fig. 1). The results showed an existence of significant difference in flower colors between Chinese Narcissus and $N$. pseudonarcissus, as well among five cultivars of $N$. pseudonarcissus, but not among four ecotypes of Chinese Narcissus.

\section{Difference analysis of morphological characteristics}

Difference analysis among nine Narcissi. For each characteristic, including average value, $\mathrm{SD}$, minimum value, maximum value, and range of variation were counted among nine narcissi and the $\mathrm{CV}$ was calculated then. As shown in Table 9, all the coefficients of variations in 24 morphological characteristics are over $10 \%$, with minimum of $12.94 \%$ in flowering stem height and maximum of $151.52 \%$ in leaf color. Eight traits, including ramet number, leaf number, plant height, leaf thickness, flowering stem height, flowering stem appearing period, flower bud coloring period, and plant withering period, demonstrate $\mathrm{CV}$ within $30 \%$. Five traits, including leaf color, catacoralla color, flower number,

Table 6. Morphological characters of inflorescence in nine narcissi.

\begin{tabular}{llcll}
\hline Narcissus & $\begin{array}{c}\text { Flowering } \\
\text { stem no. }\end{array}$ & $\begin{array}{c}\text { Flowering } \\
\text { stem ht }(\mathrm{cm})\end{array}$ & $\begin{array}{c}\text { Flowering stem } \\
\text { strength }(\mathrm{N})\end{array}$ & \multicolumn{1}{c}{ Flower no. } \\
\hline Shangnong Wanxia & $1.60 \pm 0.22 \mathrm{ab}^{z}$ & $30.05 \pm 1.12 \mathrm{c}$ & $113.43 \pm 5.67 \mathrm{a}$ & $1.60 \pm 0.22 \mathrm{a}$ \\
Shangnong Zaochun & $1.00 \pm 0.00 \mathrm{a}$ & $25.79 \pm 0.53 \mathrm{~b}$ & $309.00 \pm 11.24 \mathrm{ef}$ & $1.00 \pm 0.00 \mathrm{a}$ \\
Shangnong Ruhuang & $1.00 \pm 0.00 \mathrm{a}$ & $30.05 \pm 1.08 \mathrm{c}$ & $285.99 \pm 13.11 \mathrm{de}$ & $1.00 \pm 0.00 \mathrm{a}$ \\
Shangnong Dieying & $1.00 \pm 0.00 \mathrm{a}$ & $26.85 \pm 0.55 \mathrm{~b}$ & $321.40 \pm 10.59 \mathrm{fg}$ & $1.00 \pm 0.00 \mathrm{a}$ \\
Shangnong Hongying & $1.20 \pm 0.13 \mathrm{ab}$ & $29.10 \pm 0.67 \mathrm{c}$ & $341.95 \pm 10.84 \mathrm{~g}$ & $1.20 \pm 0.13 \mathrm{a}$ \\
Zhangzhou 'Yulinglong' & $3.60 \pm 0.40 \mathrm{c}$ & $35.13 \pm 0.60 \mathrm{~d}$ & $284.94 \pm 10.46 \mathrm{de}$ & $21.30 \pm 1.33 \mathrm{c}$ \\
Zhangzhou 'Jinzhanyintai' & $4.80 \pm 0.25 \mathrm{~d}$ & $33.99 \pm 0.60 \mathrm{~d}$ & $261.17 \pm 9.53 \mathrm{~cd}$ & $22.20 \pm 0.81 \mathrm{c}$ \\
Putuo 'Jinzhanyintai' & $5.10 \pm 0.31 \mathrm{~d}$ & $30.25 \pm 0.51 \mathrm{c}$ & $147.92 \pm 5.15 \mathrm{~b}$ & $31.70 \pm 1.71 \mathrm{~d}$ \\
Chongming 'Jinzhanyintai' & $1.80 \pm 0.13 \mathrm{~b}$ & $23.06 \pm 0.72 \mathrm{a}$ & $245.43 \pm 11.90 \mathrm{c}$ & $6.20 \pm 0.71 \mathrm{~b}$
\end{tabular}

${ }^{\mathrm{z}}$ The different lowercase letter in the same column indicates significant difference by Duncan's multiple range test at $P<0.05$.

Table 7. Flower characteristics of nine narcissi.

\begin{tabular}{lcccc}
\hline Narcissus & $\begin{array}{c}\text { Flower } \\
\text { diam }(\mathrm{cm})\end{array}$ & $\begin{array}{c}\text { Catacorolla } \\
\text { diam }(\mathrm{cm})\end{array}$ & $\begin{array}{c}\text { Petal } \\
\text { length }(\mathrm{cm})\end{array}$ & $\begin{array}{c}\text { Petal } \\
\text { width }(\mathrm{cm})\end{array}$ \\
\hline Shangnong Wanxia & $9.35 \pm 0.15 \mathrm{~d}^{z}$ & $3.09 \pm 0.08 \mathrm{~b}$ & $4.20 \pm 0.09 \mathrm{~d}$ & $3.41 \pm 0.10 \mathrm{c}$ \\
Shangnong Zaochun & $9.66 \pm 0.16 \mathrm{~d}$ & $5.31 \pm 0.08 \mathrm{~d}$ & $4.03 \pm 0.06 \mathrm{c}$ & $3.03 \pm 0.05 \mathrm{~b}$ \\
Shangnong Ruhuang & $10.55 \pm 0.10 \mathrm{e}$ & $5.47 \pm 0.09 \mathrm{~d}$ & $4.47 \pm 0.05 \mathrm{e}$ & $3.97 \pm 0.15 \mathrm{~d}$ \\
Shangnong Dieying & $8.40 \pm 0.09 \mathrm{c}$ & $6.47 \pm 0.09 \mathrm{e}$ & $3.23 \pm 0.04 \mathrm{~b}$ & $3.00 \pm 0.14 \mathrm{~b}$ \\
Shangnong Hongying & $8.90 \pm 0.10 \mathrm{c}$ & $4.16 \pm 0.08 \mathrm{c}$ & $3.96 \pm 0.05 \mathrm{c}$ & $3.87 \pm 0.16 \mathrm{~d}$ \\
Zhangzhou 'Yulinglong' & $4.26 \pm 0.06 \mathrm{~b}$ & $2.93 \pm 0.07 \mathrm{~b}$ & $1.70 \pm 0.05 \mathrm{a}$ & $1.41 \pm 0.03 \mathrm{a}$ \\
Zhangzhou 'Jinzhanyintai' & $3.97 \pm 0.06 \mathrm{ab}$ & $1.49 \pm 0.01 \mathrm{a}$ & $1.61 \pm 0.02 \mathrm{a}$ & $1.50 \pm 0.04 \mathrm{a}$ \\
Putuo 'Jinzhanyintai' & $4.10 \pm 0.05 \mathrm{ab}$ & $1.56 \pm 0.02 \mathrm{a}$ & $1.61 \pm 0.02 \mathrm{a}$ & $1.49 \pm 0.03 \mathrm{a}$ \\
Chongming 'Jinzhanyintai' & $3.85 \pm 0.07 \mathrm{a}$ & $1.56 \pm 0.03 \mathrm{a}$ & $1.63 \pm 0.03 \mathrm{a}$ & $1.45 \pm 0.06 \mathrm{a}$ \\
\hline
\end{tabular}

${ }^{\mathrm{z}}$ The different lowercase letter in the same column indicates significant difference by Duncan's multiple range test at $P<0.05$

petal color, and flower bud color, display $\mathrm{CV}$ over $100 \%$ along with the remaining eleven traits in the range from $30 \%$ to $99 \%$.

Difference analysis between two sections of Narcissus. The difference between two sections of Narcissus has been shown in Table 10. For the section Pseudonarcissus, there are obvious differences in seven characteristics, including flowering stem strength, flower bud coloring period, full blossom period, flower bud color, caracoralla color, petal color, and leaf color, with the $\mathrm{CV}$ ranging from $33.33 \%$ to $91.67 \%$. Five characteristics, including plant height, flowering stem strength, flower diameter, sprouting period, and plant withering period, show lower coefficients of variation (less than $10 \%$ ). For the section Tazetta, there exist obvious differences in only five characteristics, including flowering stem number, flower number, caracoralla diameter, early blossom period, and full blossom period, with the $\mathrm{CV}$ ranging from $37.04 \%$ to $51.79 \%$. No differences in flower bud color, catacoralla color, petal color, and leaf color are present. Their flower diameter, flowering stem appearing period, flower bud coloring period, and plant withering period are also in the lowest range in terms of $\mathrm{CV}$ (less than 10\%).

\section{The cluster analysis on the morphological level}

In the dendrogram obtained with morphological characteristics (Fig. 2), one cluster corresponds to four ecotypes of Chinese Narcissus and the other to five cultivars of $N$. pseudonarcissus (Fig. 2A). At first, the cluster analysis was performed based on eight characteristics of vegetable organs. Among Chinese Narcissus, the first group is formed between Zhangzhou Narcissus 'Jinzhanyintai' and Putuo Narcissus 'Jinzhanyintai', because there are no significant differences in five characteristics between them. Zhangzhou Narcissus 'Yulinglong' then joins the group for the uniformity in three characteristics. Chongming Narcissus 'Jinzhanyintai' is obviously different from other Chinese Narcissus, so it appears on top of this subcluster. For $N$. pseudonarcissus, there are no differences in four characteristics between 'Shangnong Dieying' and 'Shangnong Wanxie', and no differences in three characteristics among 'Shangnong Zaochun', 'Shangnong Ruhuang',

Table 8. Flower color of nine narcissi.

\begin{tabular}{llll}
\hline & \multicolumn{1}{c}{$\begin{array}{c}\text { Flower bud color and } \\
\text { RHSCC code }\end{array}$} & $\begin{array}{c}\text { Petal color and } \\
\text { RHSCC code }\end{array}$ \\
\hline $\begin{array}{l}\text { Shangnong Wanxia } \\
\text { Shangnong Zaochun }\end{array}$ & Light yellow-green, RHS150B & Yellow, RHS6A & Light yellow, RHS4D \\
Shangnong Ruhuang & Light yellow-green, RHS2D & Yellow, RHS12A & Yellow, RHS6A \\
Shangnong Dieying & Yellow, RHS4A & Yellow, RHS7D & Light yellow, RHS4D \\
Shangnong Hongying & Yellow, RHS4A & Orange, RHS14A & Light yellow, RHS4D \\
& Yellow, RHS4A & Orange for top catacorrlla, RHS24A, & Yellow, RHS6A \\
Zhangzhou 'Yulinglong' & & and yellow for bottle catacorolla, RHS12A & White, RHS155C \\
Zhangzhou 'Jinzhanyintai' & White, RHS155C & Yellow, RHS12A & White, RHS155C \\
Putuo 'Jinzhanyintai' & White, RHS155C & Yellow, RHS12A & White, RHS155C \\
Chongming 'Jinzhanyintai' & White, RHS155C & Yellow, RHS12A & White, RHS155C \\
\hline
\end{tabular}

RHSCC $=$ Royal Horticultural Society Color Card. 

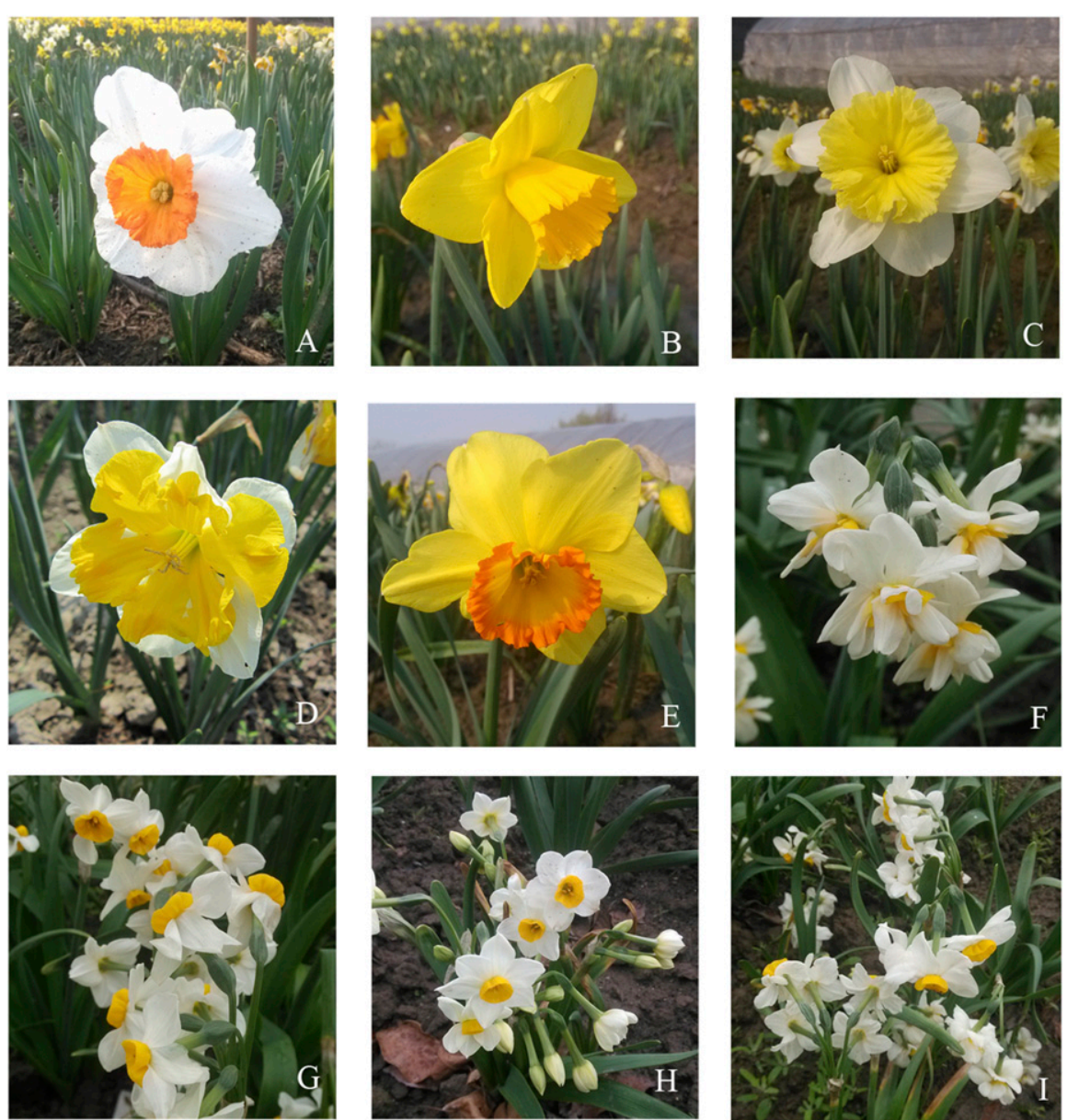

Fig. 1. Flower color of nine narcissi. (A) 'Shangnong Wanxia', (B) 'Shangnong Zaochun', (C) 'Shangnong Ruhuang', (D) 'Shangnong Dieying', (E) 'Shangnong Hongying', (F) Zhangzhou 'Yulinglong', (G) Zhangzhou 'Jinzhanyintai', (H) Putuo 'Jinzhanyintai', (I) Chongming 'Jinzhanyintai'.

Table 9. Difference analysis in 24 morphological characteristics of nine narcissi.

\begin{tabular}{lrrrrrr}
\hline & Avg & \multicolumn{1}{c}{ SD } & $\begin{array}{c}\text { Minimum } \\
\text { value }\end{array}$ & $\begin{array}{r}\text { Maximum } \\
\text { value }\end{array}$ & $\begin{array}{r}\text { Range of } \\
\text { variation }\end{array}$ & $\begin{array}{c}\text { Coefficient of } \\
\text { variation (\%) }\end{array}$ \\
\hline Ramet number & 3.58 & 1.00 & 2.50 & 5.30 & 2.80 & 27.93 \\
Leaf number & 12.79 & 3.75 & 8.00 & 18.40 & 10.40 & 29.32 \\
Plant height (cm) & 33.21 & 7.58 & 27.79 & 51.52 & 23.73 & 22.82 \\
Leaf width (cm) & 2.11 & 0.73 & 1.10 & 3.12 & 2.02 & 34.60 \\
Leaf thickness (mm) & 1.24 & 0.33 & 0.84 & 1.72 & 0.88 & 26.61 \\
Flowering stem number & 2.34 & 1.69 & 1.00 & 5.10 & 4.10 & 72.22 \\
Flowering stem height (cm) & 29.37 & 3.80 & 23.06 & 35.13 & 12.07 & 12.94 \\
Flowering stem strength (N) & 256.25 & 77.52 & 113.43 & 341.95 & 228.52 & 30.25 \\
Flower number & 9.69 & 12.00 & 1.00 & 31.70 & 30.70 & 123.84 \\
Flower diameter (cm) & 7.00 & 2.87 & 3.85 & 10.55 & 6.70 & 41.00 \\
Catacorolla diameter (cm) & 3.56 & 1.89 & 1.49 & 6.47 & 4.98 & 53.09 \\
Petal length (cm) & 2.94 & 1.28 & 1.61 & 4.47 & 2.86 & 43.54 \\
Petal width (cm) & 2.57 & 1.10 & 1.41 & 3.97 & 2.56 & 42.80 \\
Germinating period & 71.67 & 36.28 & 30.00 & 111.00 & 81.00 & 50.62 \\
Flowering stem appearing period & 16.00 & 3.87 & 13.00 & 24.00 & 11.00 & 24.19 \\
Flower bud coloring period & 13.44 & 3.28 & 8.00 & 19.00 & 11.00 & 24.40 \\
Early blossom period & 4.56 & 3.88 & 1.00 & 10.00 & 9.00 & 85.09 \\
Full blossom period & 3.22 & 1.30 & 2.00 & 6.00 & 4.00 & 40.37 \\
Late blossom period & 11.67 & 4.92 & 6.00 & 21.00 & 15.00 & 42.16 \\
Plant withering period & 41.89 & 10.43 & 30.00 & 57.00 & 27.00 & 24.90 \\
Flower bud color & 1.33 & 1.414 & 0 & 3 & 3 & 106.32 \\
Catacoralla color & 1.11 & 1.537 & 0 & 4 & 4 & 138.47 \\
Petal color & 0.78 & 0.833 & 0 & 2 & 2 & 106.79 \\
Leaf color & 0.33 & 0.5 & 0 & 1 & 1 & 151.52 \\
\hline
\end{tabular}

and 'Shangnong Hongying'. So there are two groups present on the bottom of this cluster, forming a subcluster to join the cluster of Chinese Narcissus.
Next, the cluster analysis was performed based on 16 characteristics of inflorescence and flower. The results are in general similar to these obtained with vegetable characteristics
(Fig. 2B). For the subcluster containing four ecotypes of Chinese Narcissus, there are three ecotypes together on the bottom, because there are no obvious differences in eight characteristics. Chongming Narcissus 'Jinzhanyintai' then joins. The other subcluster corresponds to five cultivars of $N$. pseudonarcissus. The first group is formed between 'Shangnong Hongying' and 'Shangnong Ruhuang' for their uniformity in six characteristics. The second class is generated between 'Shangnong Zaochun' and 'Shangnong Dieying' because of their uniformity in five characteristics. More differences present between 'Shangnong Wanxie' and others, so they join the subcluster at last.

When all 24 morphological characteristics were taken into consideration, two similar clusters were also obtained (Fig. 2C). By comparing with the results obtained from the characteristics of inflorescence and flower, only one order in the subcluster corresponding to $N$. pseudonarcissus shows difference, revealing the importance of subset of characteristics in the cluster analysis.

\section{Evaluating the genetic diversity with RAPD markers among nine narcissi}

DNA quality was confirmed by gel electrophoresis and absorbances at optical density $260\left(\mathrm{OD}_{260}\right)$ and $\mathrm{OD}_{280}\left(\mathrm{OD}_{260} / \mathrm{OD}_{280}\right.$ : 1.9-2.0). The determined DNA concentration was in the range of $255-405 \mathrm{ng} / \mu \mathrm{L}$.

Forty RAPD primers were first chosen according to previous reports (Chen et al., 2002, 2003; Dong, 2012; Zhu, 2003), in which these 10 -mer primers were proved to be good for Narcissus. Of these 40 RAPD primers initially screened, 13 primers were selected on the basis of robustness of amplification, reproducibility, and scorability of banding patterns (data not shown) and used for the amplification of all DNA samples and the diversity analysis among nine narcissi. All amplifications were repeated twice, and only bands amplified in both duplicates were scored. The results showed a total of 95 clearly scorable fragments $(0.25-3 \mathrm{~kb}$ in length) amplified in nine narcissi (Table 11; Fig. 3). For each primer, the band number differs from 4 to 14 with an average value of 7.3. The number of bands with high polymorphism is 81 and the percentage of polymorphic bands is $85.3 \%$.

Band scores were used for cluster analysis and dendrograms produced based on the coefficients. As shown in Fig. 4, there are two groups in the dendrogram, one contains five cultivars of $N$. pseudonarcissus and the other four ecotypes of Chinese Narcissus. For $N$. pseudonarcissus, 'Shangnong Wanxia' and 'Shangnong Ruhuang', 'Shangnong Dieying' and 'Shangnong Hongying' are first clustered to two subgroups, which are then merged to another group. 'Shangnong Zaochun' joins the group at last for its greater differences with other cultivars. For Chinese Narcissus, three ecotypes with single petals are grouped together, then combined with Zhangzhou Narcissus 'Yulinglong', which possesses double petals. 
Based on RAPD markers, the genetic similarity (GS) of the nine narcissi was analyzed further by the similarity matrix (Table 12). The GS varies from 0.2737 to 0.9579 among all materials with a mean value of 0.5854 . The GS values for $N$. pseudonarcissus members are similar within a narrow range from 0.7474 to 0.8947 . And the GS values for
Chinese Narcissus are also similar within an even narrow range from 0.8947 to 0.9579 . The results revealed a close genetic relationship within the five cultivars of $N$. pseudonarcissus and four ecotypes of Chinese Narcissus, respectively. However, the genetic distance between the two sections is far as indicated by the small GS values $(0.2737-0.3684)$.

Table 10. Difference analysis in 24 morphological characters between two sections of narcissus.

\begin{tabular}{|c|c|c|c|c|c|c|}
\hline \multirow[b]{2}{*}{ Characteristic } & \multicolumn{3}{|c|}{ Cultivars in section Pseudonarcissus } & \multicolumn{3}{|c|}{ Ecotypes in section Tazetta } \\
\hline & Avg & SD & $\begin{array}{l}\text { Coefficient of } \\
\text { variation }(\%)\end{array}$ & Avg & SD & $\begin{array}{l}\text { Coefficient of } \\
\text { variation }(\%)\end{array}$ \\
\hline Ramet number & 2.92 & 0.33 & 11.30 & 4.40 & 0.94 & 21.36 \\
\hline Leaf number & 10.50 & 2.75 & 26.19 & 15.65 & 2.79 & 17.83 \\
\hline Plant height $(\mathrm{cm})$ & 29.82 & 1.45 & 4.86 & 37.45 & 10.35 & 27.64 \\
\hline Leaf width $(\mathrm{cm})$ & 1.58 & 0.43 & 27.22 & 2.78 & 0.33 & 11.87 \\
\hline Leaf thickness (mm) & 0.99 & 0.17 & 17.17 & 1.55 & 0.17 & 10.97 \\
\hline Flowering stem number & 1.16 & 0.26 & 22.41 & 3.83 & 1.50 & 39.16 \\
\hline Flowering stem height $(\mathrm{cm})$ & 28.37 & 1.95 & 6.87 & 30.61 & 5.45 & 17.80 \\
\hline Flowering stem strength $(\mathrm{N})$ & 273.35 & 92.08 & 33.69 & 234.87 & 60.20 & 25.63 \\
\hline Flower number & 1.16 & 0.26 & 22.41 & 20.35 & 10.54 & 51.79 \\
\hline Flower diameter $(\mathrm{cm})$ & 9.37 & 0.81 & 8.64 & 4.05 & 0.18 & 4.44 \\
\hline Catacorolla diameter $(\mathrm{cm})$ & 4.90 & 1.30 & 26.53 & 1.89 & 0.70 & 37.04 \\
\hline Petal length $(\mathrm{cm})$ & 3.98 & 0.46 & 11.56 & 1.64 & 0.43 & 26.22 \\
\hline Petal width $(\mathrm{cm})$ & 3.46 & 0.45 & 13.01 & 1.46 & 0.41 & 28.08 \\
\hline Sprouting period & 102.00 & 5.83 & 5.72 & 33.75 & 3.78 & 11.20 \\
\hline $\begin{array}{l}\text { Flowering stem } \\
\text { appearing period }\end{array}$ & 17.60 & 4.72 & 26.82 & 14.00 & 0.82 & 5.86 \\
\hline Flower bud coloring period & 12.60 & 4.39 & 34.84 & 14.50 & 0.58 & 4.00 \\
\hline Early blossom period & 2.20 & 0.45 & 20.45 & 7.50 & 4.36 & 58.13 \\
\hline Full blossom period & 3.00 & 1.00 & 33.33 & 3.50 & 1.73 & 49.43 \\
\hline Late blossom period & 8.40 & 1.67 & 19.88 & 15.75 & 4.57 & 29.02 \\
\hline Plant withering period & 50.20 & 4.55 & 9.06 & 31.50 & 1.92 & 6.10 \\
\hline Flower bud color & 2.40 & 0.89 & 37.08 & 0.00 & 0.00 & 0.00 \\
\hline Catacoralla color & 2.00 & 1.58 & 79.00 & 0.00 & 0.00 & 0.00 \\
\hline Petal color & 1.40 & 0.55 & 39.29 & 0.00 & 0.00 & 0.00 \\
\hline Leaf color & 0.60 & 0.55 & 91.67 & 0.00 & 0.00 & 0.00 \\
\hline
\end{tabular}

\section{Discussion}

In the genus Narcissus, which possesses the huge germplasm resources (Kington, 2014), studies on germination, growth, propagation, cultivation, and breeding have been conducted widely on morphological level (Copete et al., 2014; Larrinaga et al., 2009; Marques et al., 2007; Medrano et al., 2005). However, the systematic and quantitative analysis of the genetic diversity based on morphological traits, especially combining molecular markers, is still ongoing (Nuñez et al., 2003; Santos-Gally et al., 2012). In the present study, first, 24 morphological characteristics for two sections of Narcissus were examined and the variability within nine narcissi was quantitatively determined. It

Table 11. The amplification results of 13 random primers.

\begin{tabular}{lccc}
\hline $\begin{array}{l}\text { Primer } \\
\text { code }\end{array}$ & $\begin{array}{c}\text { No. of } \\
\text { bands }\end{array}$ & $\begin{array}{c}\text { No. of } \\
\text { polymorphic } \\
\text { bands }\end{array}$ & $\begin{array}{c}\text { Percentage of } \\
\text { polymorphic } \\
\text { bands (\%) }\end{array}$ \\
\hline S10 & 14 & 10 & 71.4 \\
S48 & 7 & 5 & 71.4 \\
S58 & 5 & 3 & 60.0 \\
S68 & 8 & 6 & 75.0 \\
S121 & 8 & 8 & 100.0 \\
S287 & 4 & 4 & 100.0 \\
S295 & 10 & 10 & 100.0 \\
S303 & 8 & 6 & 75.0 \\
S340 & 8 & 6 & 75.0 \\
S476 & 7 & 7 & 100.0 \\
S1510 & 5 & 5 & 100.0 \\
S1520 & 5 & 5 & 100.0 \\
S1521 & 6 & 6 & 100.0 \\
Total & 95 & 81 & 85.3 \\
\hline
\end{tabular}

A
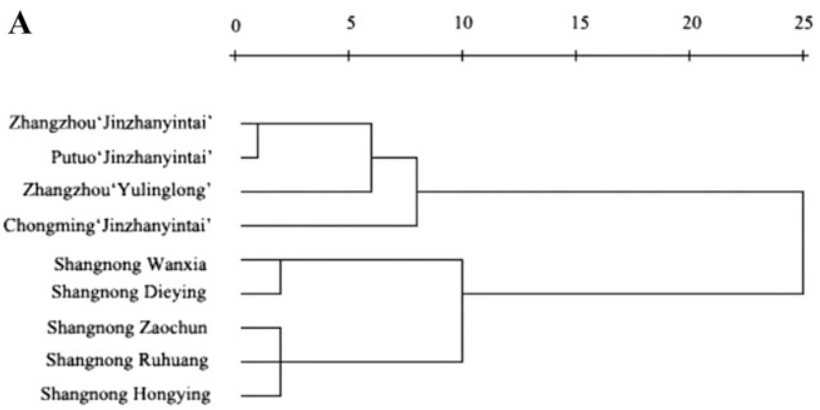

B

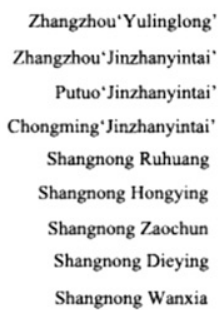

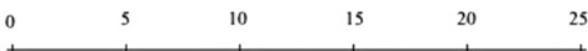

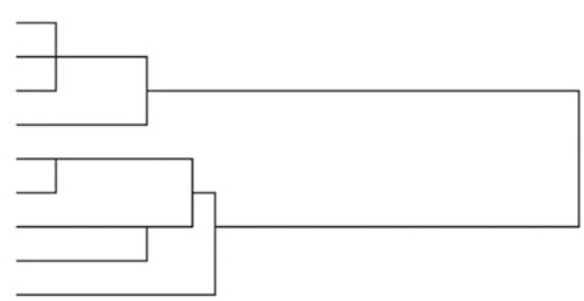

C

Rescaled Distance Cluster Combine

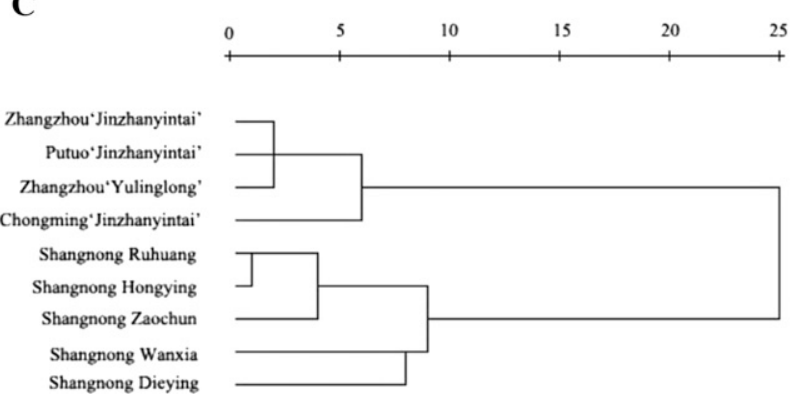

Fig. 2. Dendrograms of clustering analysis based on (A) agro-morphological characteristics of vegetative organs, (B) morphological characteristics of inflorescence and flower, and (C) total 24 morphological characteristics. 

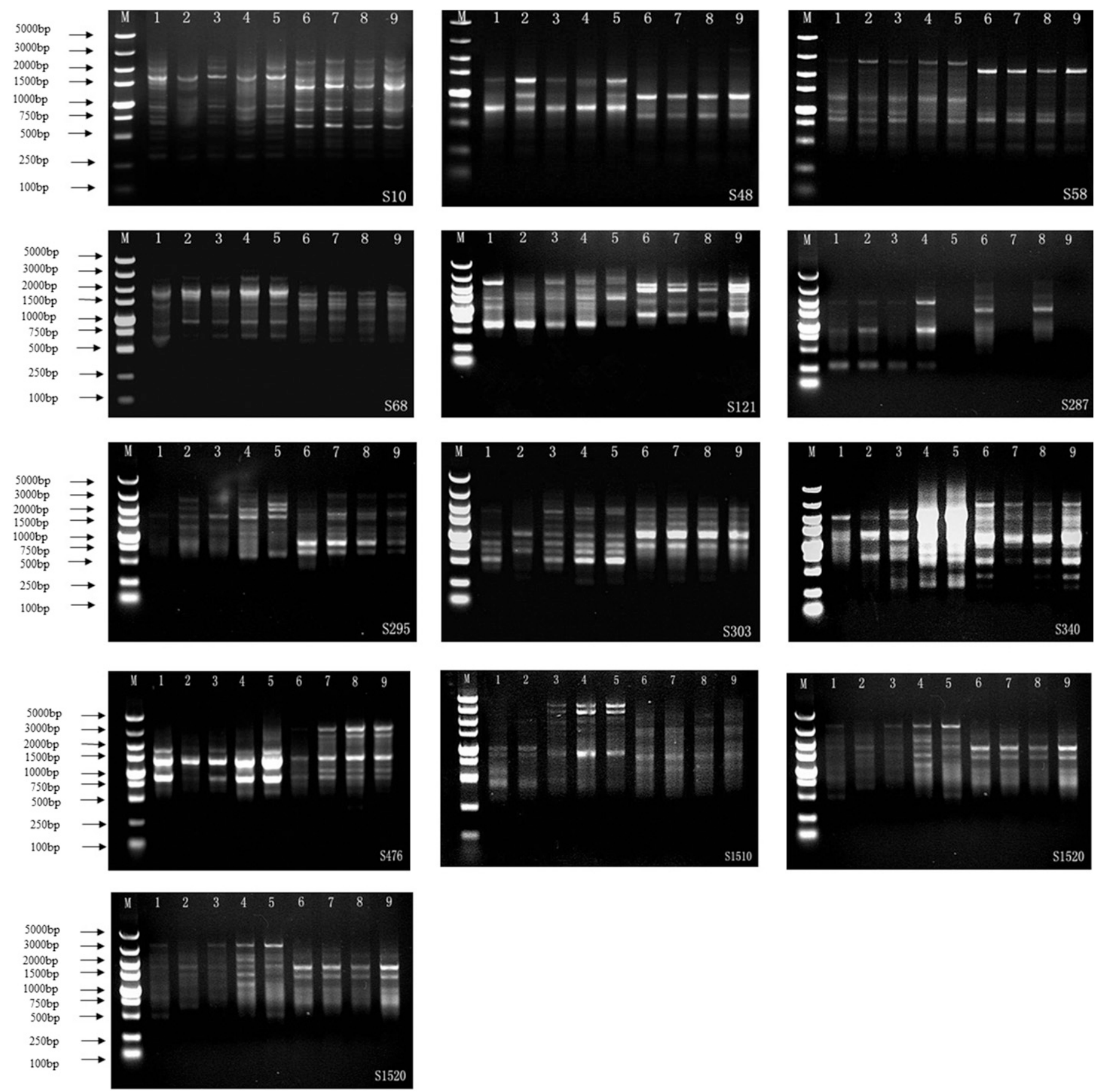

Fig. 3. The gel photographs obtained with 13 random primers. Note for Lanes: M, DL5,000 DNA marker; 1, 'Shangnong Wanxia'; 2, 'Shangnong Zaochun'; 3 , 'Shangnong Ruhuang'; 4, 'Shangnong Dieying'; 5, 'Shangnong Hongying'; 6, Zhangzhou 'YuLinglong'; 7, Zhangzhou 'Jinzhanyintai'; 8, Putuo 'Jinzhanyintai'; 9, Chongming 'Jinzhanyintai'.

turns out that plenty of genetic diversity exists among these narcissi, and N. pseudonarcissus shares few common morphological traits with Chinese Narcissus. In fact, 16 out of the 24 morphological traits $(66.7 \%)$ display $\mathrm{CV}$ over $30 \%$, which could be helpful to select the objective traits in future cross breeding. Within individual section, five cultivars in the section Pseudonarcissus exhibit a wide range of genetic diversity on the morphological level, which could result from a long history of hybridization from many cross parents. On the contrary, four ecotypes of Chinese Narcissus show a similar overall morphology, especially in flower traits, this loss of genetic diversity might be due to their belonging to a monophyletic group and partially its triploid feature which possessed hard acceptance for new genes (Lu et al., 2007). These results show a wide morphological variability within two sections of Narcissus and share a broad agreement with previous studies (Colling et al., 2010; Marques et al., 2007; Santos-Gally et al., 2012). The cluster analysis based on the 24 morphological characteristics showed that these narcissi were divided obviously into two groups, corresponding to the two sections, validating the evaluation method of genetic relationship and genetic diversity based on the morphological level in Narcissus.

Molecular markers, such as RAPDs, are powerful in analyzing genetic relation and diversity, and evaluating taxonomic identity of plants (Colling et al., 2010; Kocsis et al., 2015; Kour et al., 2016; Wu et al., 2005). The cluster analysis based on RAPD markers revealed a distant genetic relationship between the two sections of Narcissus, whereas a close relationship within individual section, sharing agreement with previous studies (Chen et al., 2002, 2003; Dong, 2012; Zhu, 


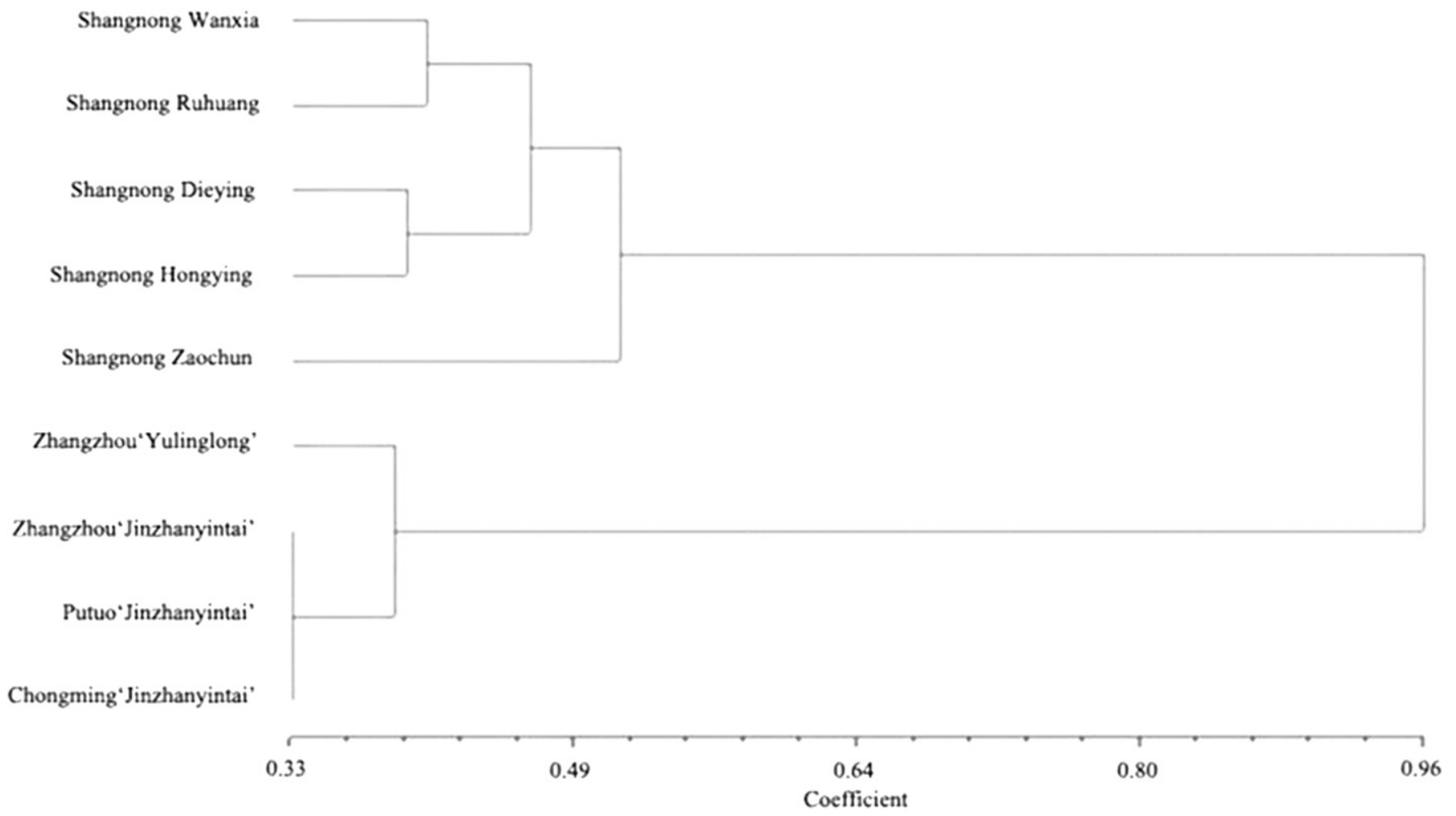

Fig. 4. Dendrogram based on random amplified polymorphic DNA (RAPD) markers illustrating the genetic relationship among the analyzed narcissi.

Table 12. Genetic similarity of nine narcissi based on RAPD markers.

\begin{tabular}{llcccccccc}
\hline & $1^{\mathrm{z}}$ & 2 & 3 & 4 & 5 & 6 & 7 & 8 & 9 \\
\hline 1 & $1.0000^{\mathrm{y}}$ & & & & & & & & \\
2 & 0.8211 & 1.0000 & & & & & & & \\
3 & 0.8842 & 0.7684 & 1.0000 & & & & & & \\
4 & 0.8000 & 0.7684 & 0.8737 & 1.0000 & & & & \\
5 & 0.7789 & 0.7474 & 0.8526 & 0.8947 & 1.0000 & & & \\
6 & 0.3368 & 0.3684 & 0.3263 & 0.3263 & 0.3263 & 1.0000 & & \\
7 & 0.3158 & 0.3684 & 0.3474 & 0.3474 & 0.3474 & 0.8947 & 1.0000 & & \\
8 & 0.2737 & 0.3474 & 0.3053 & 0.3263 & 0.3263 & 0.9158 & 0.9579 & 1.0000 & 1.0000 \\
9 & 0.2737 & 0.3474 & 0.3263 & 0.3474 & 0.3474 & 0.8947 & 0.9579 & 0.9579 &
\end{tabular}

RAPD = random amplified polymorphic DNA.

z1, 'Shangnong Wanxia'; 2, 'Shangnong Zaochun'; 3, 'Shangnong Ruhuang'; 4, 'Shangnong Dieying'; 5, 'Shangnong Hongying'; 6, Zhangzhou 'Yulinglong'; 7, Zhangzhou 'Jinzhanyintai'; 8, Putuo 'Jinzhanyintai'; 9, Chongming 'Jinzhanyintai'.

${ }^{\mathrm{y}}$ Similarity coefficient.

2003). In other words, a low level of genetic diversity has been observed within individual section, especially for Chinese Narcissus. The two groups generated based on RAPDs are consistent mostly with that based on morphological characteristics, confirming the validity of the analysis method of genetic diversity both on the morphological level and DNA level for narcissus. However, the relations within individual section, as revealed by RAPD markers, are not significantly correlated with those based on the morphological characteristics, suggesting that the two systems still give different estimates of genetic relations at some degree. Based on RAPD markers, three ecotypes with single petals in Chinese Narcissus, including Zhangzhou narcissus 'Jinzhanyintai', Putuo narcissus 'Jinzhanyintai', and Chongming narcissus 'Jinzhanyintai', show no genetic diversity, which is consistent with the previous botanical taxonomy (Lu et al., 2007) and suggest these ecotypes should be same on DNA level. However, Chongming narcissus 'Jinzhanyintai' joins the cluster at last based on morphological characteristics, which is inconsistent with that on DNA level, revealing it is distinct from other three ecotypes of Chinese Narcissus on morphological level. The inconsistent result between RAPDs and morphological characteristics may have arisen because the traits of this ecotype have changed much at the morphological level during a long adaptive to local climate and soil conditions, which may reflect occurrence of epigenetic modifications in the species.

Analysis of the morphological traits and RAPD markers indicates that the genetic relationships among the five cultivars in the section Pseudonarcissus are variable. Shangnong Ruhuang and Shangnong Hongying, two large-cupped cultivars, are similar in many morphological traits, whereas different in some morphological traits with another largecupped cultivar (Shangnong Wanxia) and the split corona cultivar (Shangnong Dieying), suggesting a close genetic relationship between these two cultivars, whereas a far relationship with other two cultivars. In addition, Shangnong Zaochun, the trumpet cultivar, exhibits a moderate different genetic relationship with other four cultivars on moderate different morphological traits. This result is consistent with previous studies (Dong, 2012; Zhu, 2003). From perspective of classification (Brickell, 2008), 'Shangnong Wanxia', 'Shangnong Ruhuang', and 'Shangnong Hongying' belong to the same division; their genetic relationship is expected to be close. This prediction is supported by RAPD cluster analysis but not exactly by the morphological trait analysis, revealing RAPD analysis may be more accurate than morphological analysis.

In conclusion, genetic diversity analysis is performed via a combined approach of morphological characteristics and RAPD technique. The methods allow a deep evaluation of the variation of Narcissus on both section level and cultivar/ecotype level. The results would be valuable for genotype identification, phylogenetic analysis, as well as for future breeding study and practice in the genus.

\section{Literature Cited}

Ambade, R.L., S.K. Verma, H.C. Nanda, S.K. Nair, and S.B. Verulkar. 2015. Genetic diversity based on molecular markers in Grasspea (Lathyrus sativus L.). Legume Res. 38(1):43-46. 
Bradakci, F. 2001. Random amplified polymorphic DNA (RAPD) markers. Turk. J. Biol. 25:185196.

Brickell, C. 2008. RHS A-Z encyclopedia of garden plants, p. 1136. Dorling Kindersley, London, UK.

Chen, L., Y. Miao, D. Chen, and H. Tian. 2002. Analysis of germplasm resources of Narcissus tazetta L. var. chinensis by RAPD. J. Xiamen Univ. (Natur. Sci.) 41(6):810-814.

Chen, L., H. Tian, and J. Wu. 2003. The study on RAPD fingerprints of narcissus in China and Europe. J. Tropical Subtropical Bot. 11(2):177-180.

Colling, G., P. Hemmer, A. Bonniot, S. Hermant, and D. Matthies. 2010. Population genetic structure of wild daffodils (Narcissus pseudonarcissus L.) at different spatial scales. Plant Syst. Evol. 287:99-111.

Copete, E., J.M. Herranz, M.Á. Copete, and P. Ferrandis. 2014. Interpopulation variability on embryo growth, seed dormancy break, and germination in the endangered Iberian daffodil Narcissus eugeniae (Amaryllidaceae). Plant Species Biol. 29:72-84.

Dong, Y. 2012. Study on fertility of Holland narcissus [D]. Shanghai Jiao Tong University.

Doyle, J.J. and J.L. Doyle. 1987. A rapid DNA isolation procedure for small amounts of fresh leaf tissue. Phytochem. Bull. 19:11-15.

Franco, J., J. Crossa, J.M. Ribaut, J. Betran, M.L. Warburton, and M. Khairallah. 2001. A method for combining molecular markers and phenotypic attributes for classifying plant genotypes. Theor. Appl. Genet. 103:944-952.

Gepts, P. 1993. The use of molecular and biochemical markers in crop evolution studies, $p$. 51-94. In: M.K. Heche (ed.). Evolutionary biology, 27. Plenum Press, New York, NY.

Hodgins, K.A. and S.C.H. Barrett. 2007. Population structure and genetic diversity in tristylous Narcissus triandrus: Insights from microsatellite and chloroplast DNA variation. Mol. Ecol. 16:2317-2332.

Idrissi, O., S.M. Udupa, C. Houasli, E. De Keyser, P.V. Damme, and J. De Riek. 2015. Genetic diversity analysis of Moroccan lentil (Lens culinaris Medik.) landraces using simple sequence repeat and amplified fragment length polymorphisms reveals functional adaptation towards agro-environmental origins. Plant Breed. 134:322-332.

Jiménez, J.F., P. Sánchez-Gómez, J. Guerra, A. Molins, and J.A. Rosselló. 2009. Regional speciation or taxonomic inflation? The status of several narrowly distributed and endangered species of narcissus using ISSR and nuclear ribosomal ITS markers. Folia Geobot. 44:145158.

Kington, S. 1998. The international daffodil register and classified list 1998. Royal Horticultural Society, London, UK.

Kington, S. 2014. The daffodil register and classified list (2008). 6th supplement. Royal Horticultural Society, London, UK.

Kocsis, M., L. Járomi, P. Putnoky, P. Kozma, and A. Borhidi. 2015. Genetic diversity among twelve grape cultivars indigenous to the Carpathian Basin revealed by RAPD markers. Vitis 44 (2):87-91.

Könyves, K., J. David, and A. Culham. 2011. Towards a reproducible system of identification for daffodil cultivars, p. 26-29. In: M.S. Bradbury, W.M. Akers, J.I. Akers, J.W. Blanchard, C.D. Brickell, B.S. Duncan, J.Gibson, G. Hanks, S. Kington, and L. Skelmersdale (eds.). Daffodil, snowdrop and tulip year book. Royal Horticultural Society, London, UK.

Kour, B., S. Kotwal, M.K. Dhar, and S. Kaul. 2016. Genetic diversity analysis in Plantago ovata and some of its wild allies using RAPD markers. Russ. Agr. Sci. 42(1):37-41.

Larrinaga, A.R., P. Guitián, J.L. Garrido, and J. Guitián. 2009. Floral morphology and reproductive success in herkogamous Narcissus cyclamineus (Amaryllidaceae). Plant Syst. Evol. 278:149-157.

Lu, G., X. Zhang, Y. Zou, Q. Zou, X. Xiang, and J. Cao. 2007. Effect of radiation on regeneration of Chinese narcissus and analysis of genetic variation with AFLP and RAPD markers. Plant Cell Tissue Organ Cult. 88:19-327.

Marić, S., S. Bolarić, J. Martinčić, I. Pejić, and V. Kozumplik. 2004. Genetic diversity of hexaploid wheat cultivars estimated by RAPD markers, morphological traits and coefficients of parentage. Plant Breed. 123:366-369.

Marques, I., A. Rosselló-Graell, D. Draper, and J.M. Iriondo. 2007. Pollination patterns limit hybridization between two sympatric species of Narcissus (Amaryllidaceae). Amer. J. Bot. 94(8):1352-1359.

Medrano, M., C.M. Herrera, and S.C.H. Barrett. 2005. Herkogamy and mating patterns in the self-compatible daffodil Narcissus longispathus. Ann. Bot. (Lond.) 95:1105-1111.

Nuñez, D.R., C.O. De Castro, S.R. Ruiz, and F.A. Ariza. 2003. The origin of cultivation and wild ancestors of daffodils (Narcissus subgenus
Ajax) (Amaryllidaceae) from an analysis of early illustrations. Sci. Hort. 98:307-330.

Patzak, J. 2001. Comparison of RAPD, STS, ISSR and AFLP molecular methods used for assessment of genetic diversity in hop (Humulus lupulus L.). Euphytica 121(1):9-18.

Rafeipour, M., G. Mirzaghaderi, S. Shaaf, and H. Badakhshan. 2016. SSR assessment of the genetic diversity of emmer wheat with emphasis on Iranian landraces (Triticum dicoccon Schrank). Genet. Resources Crop Evol. 63:595-600.

Santos-Gally, R., P. Vargas, and J. Arroyo. 2012. Insights into Neogene Mediterranean biogeography based on phylogenetic relationships of mountain and lowland lineages of Narcissus. J. Biogeogr. 39:782-798.

Singh, S.P., J.A. Gutiérrez, A. Molina, C. Urrea, and P. Gepts. 1991. Genetic diversity in cultivated common bean: II. Marker-based analysis of morphological and agronomic traits. Crop Sci. 31:23-29.

Tar'an, B., C. Zhang, T. Warkentin, A. Tullu, and A. Vandenberg. 2005. Genetic diversity among varieties and wild species accessions of pea (Pisum sativum L.) based on molecular markers, and morphological and physiological characters. Genome 48(2):257-272.

Tatineni, V., R.G. Cantrell, and D.D. Davis. 1996. Genetic diversity in Elite cotton germplasm determined by morphological characteristics and RAPDs. Crop Sci. 36(1):186-192.

Tucci, G.F., M.O. Winfield, G.F. D'Amato, C. Gregori, B. Trombetta, and R.I. De Dominicis. 2004. Genetic diversity in Narcissus poëticus L. and N. radiiflorus Salisb. (Amaryllidaceae) in two different populations: AFLP and karyological studies. Caryologia 57(4):405-411.

Warwick, S.I., R.K. Gugel, T. McDonald, and K.C. Falk. 2006. Genetic variation of Ethiopian mustard (Brassica carinata A. Braun) germplasm in western Canada. Genet. Resources Crop Evol. 53(2):297-312.

Wu, J., L. Lu, and Z. Zhang. 2005. A study on genetic relationship among several narcissus cultivars by RAPD markers. Chinese Agr. Sci. Bull. 21(8):299-301.

Zhang, L.J. and S.L. Dai. 2010. Genetic variation within and among populations of Orychophragmus violaceus (Cruciferae) in China as detected by ISSR analysis. Genet. Resources Crop Evol. 57:55-64.

Zhu, Z. 2003. Study on polygenetic relationship of narcissus by molecular markers [D]. Nanjing Agricultural University. 